\title{
Carbon monoxide poisoning surveillance in the Veterans Health Administration, 2010-2017
}

\author{
Gina Oda ${ }^{1 *} \mathbb{D}$, Russell Ryono ${ }^{1}$, Cynthia Lucero-Obusan ${ }^{1}$, Patricia Schirmer $^{1}$ and Mark Holodniy ${ }^{1,2}$
}

\begin{abstract}
Background: Exposure to carbon monoxide (CO), the odorless, colorless gas resulting from incomplete combustion of hydrocarbons, is preventable. Despite the significant risk of morbidity and mortality associated with CO poisoning, there currently exists no active national CO surveillance system in the United States (U.S.). Our study aims to use electronic health record data to describe the epidemiology of CO poisoning in the Veterans Health Administration healthcare population.
\end{abstract}

Methods: We identified unique inpatient and outpatient encounters coded with International Classification of Diseases (ICD) codes for CO poisoning and analyzed relevant demographic, laboratory, treatment, and death data from January 2010 through December 2017 for Veterans across all 50 U.S. states and Puerto Rico. Statistical methods used were 95\% $\mathrm{Cl}$ calculations and the two-tailed $\mathrm{z}$ test for proportions.

Results: We identified 5491 unique patients with CO poisoning, of which 1755 (32\%) were confirmed/probable and 3736 (68\%) were suspected. Unintentional poisoning was most common (72.9\%) overall. Age less than 65 years, residence in Midwest U.S. Census region versus South or West, and winter seasonal trend were characteristics associated with confirmed/probable CO poisoning. Twenty-six deaths (1.5\%) occurred within 30 days of confirmed/probable CO poisoning and were primarily caused by cardiovascular events (42\%) or anoxic encephalopathy (15\%).

Conclusions: Our findings support the use of ICD-coded data for targeted CO poisoning surveillance, however, improvements are needed in ICD coding to reduce the percentage of cases coded with unknown injury intent and/or CO poisoning source. Prevalence of CO poisoning among Veterans is consistent with other U.S. estimates. Since most cases are unintentional, opportunities exist for provider and patient education to reduce risk.

Keywords: Carbon monoxide poisoning, Veterans health, Public health, Surveillance, Epidemiology, Toxicology, Environmental exposures

\section{Background}

Exposure to carbon monoxide (CO), the odorless, colorless gas resulting from incomplete combustion of hydrocarbons, is avoidable. However, $\mathrm{CO}$ poisoning is one of the most common causes of unintentional poisoning deaths in the U.S. $[1,2]$ It is estimated that unintentional, non-fire related (UNFR) CO poisoning causes an average of 438 deaths annually. In 2007, confirmed CO

\footnotetext{
* Correspondence: gina.oda@va.gov; Gina.oda@va.gov

${ }^{1}$ Public Health Surveillance and Research, Department of Veterans Affairs, 3801 Miranda Avenue (132), Palo Alto, CA 94304, USA

Full list of author information is available at the end of the article
}

poisoning cases resulted in 21,304 U.S. emergency department (ED) visits and 2302 hospitalizations (71 per million and 8 per million population, respectively) [3]. However, other analyses estimate that over 50,000 ED visits for $\mathrm{CO}$ poisoning occur annually, which may still be an underestimate because the condition is underdiagnosed [4]. Data reported to the National Poison Data System estimates that UNFR CO poisoning exposures occur at a rate of 23.2 per million population per year [1]. Despite the significant risk of morbidity and mortality associated with $\mathrm{CO}$ poisoning, there currently exists no active national CO surveillance system in the U.S. [5]

(c) The Author(s). 2019 Open Access This article is distributed under the terms of the Creative Commons Attribution 4.0 International License (http://creativecommons.org/licenses/by/4.0/), which permits unrestricted use, distribution, and reproduction in any medium, provided you give appropriate credit to the original author(s) and the source, provide a link to the Creative Commons license, and indicate if changes were made. The Creative Commons Public Domain Dedication waiver (http://creativecommons.org/publicdomain/zero/1.0/) applies to the data made available in this article, unless otherwise stated. 
Studies utilizing administrative data for case-finding generally do not include more current International Classification of Diseases, 10th revision, Clinical Modification (ICD-10-CM) coded data for comparison ICD-9-CM-based estimates [6, 7].

Limited data exist on population risk factors that predispose to $\mathrm{CO}$ poisoning. Additionally, $\mathrm{CO}$ poisoning as a suicide method is not well studied. Few local/state-based $\mathrm{CO}$ poisoning surveillance systems include intentional $\mathrm{CO}$ poisonings [8-10], and data examined are often limited to post-mortem datasets such as the National Death Index or state Medical Examiner records. Therefore, a complete understanding of $\mathrm{CO}$ poisoning-associated suicide attempts is lacking.

The Veterans Health Administration (VHA), within the Department of Veterans Affairs (VA) is the largest integrated health care system in the U.S., providing care to over 9 million enrolled Veterans at 172 hospitals and 1062 outpatient sites across all 50 states, District of Columbia, and U.S. territories [11]. Veterans are at risk for smoking and cardiovascular disease [12, 13] which could place them at higher risk for adverse outcomes from CO poisoning [14]. Veterans are also at increased risk for suicide $[15,16]$, however, $\mathrm{CO}$ poisoning as a suicide method in this population has not been studied. Sharp decreases occurred among the general population in $\mathrm{CO}$ poisoning suicides associated with motor vehicle exhaust since the introduction of stricter automobile emissions $[17,18]$. Given that $\mathrm{CO}$ poisoning causes serious morbidity and mortality, a better understanding of $\mathrm{CO}$ poisoning trends among Veterans is critical. The goal of this study is to describe the epidemiology of $\mathrm{CO}$ poisoning among Veterans cared for in VHA using national integrated electronic health record data.

\section{Methods}

\section{Study population}

We analyzed VA electronic medical record (EMR) data for inpatient discharges and outpatient encounters from January 2010 through December 2017 with ICD-9-CM or ICD-10-CM codes meeting the 2018 Council of State and Territorial Epidemiologists (CSTE) criteria for CO poisoning case ascertainment using administrative data [19]. Veterans receiving care at non-VA healthcare facilities during the study period and whose coded encounters met CSTE criteria for CO poisoning were included. Patients with multiple visits classified as $\mathrm{CO}$ poisoning during the study period were counted once, for their initial encounter. Demographic, laboratory, and treatment data, and date of death (where applicable) recorded in the EMR for each unique patient with $\mathrm{CO}$ poisoning for the study time-period was collected. $\mathrm{CO}$ poisoning surveillance was conducted as part of VHA public health operations. As such, the Veterans Health Administration
Office of Research Oversight considers public health investigations as operational activities and not research in VHA [20].

If patients had outpatient and inpatient codes for the same day, one unique encounter was counted, with highest level of care (i.e., inpatient) selected. To reduce inclusion of patients whose ICD-9-CM code was not indicative of initial exposure, we reviewed patient problem lists and removed 34 patients whose coded problem list indicated exposure to $\mathrm{CO}$ occurred prior to the study period. For patient encounters with ICD-10-CM codes, we reviewed the seventh character extension to determine if the encounter was deemed initial, subsequent, or related to $\mathrm{CO}$ poisoning sequela and a query was performed to determine if any of these patients had $\mathrm{CO}$ poisoning-coded visits prior to 2010. One patient with an ICD-10-CM sequela episode of care extension had an initial encounter in 2004 and was removed.

Based on 2018 CSTE criteria utilizing ICD-9-CM and ICD-10-CM codes, unique patients were classified by degree of certainty that poisoning was CO-related (confirmed, probable, suspected). A case was considered confirmed if the inpatient discharge or outpatient encounter was coded with ICD-9-CM code 986 or ICD-10-CM code T58 (toxic effect of carbon monoxide); or with an ICD-9-CM External Cause of Injury code (E-code) explicitly indicating $\mathrm{CO}$ exposure was present in the absence of code 986 (E868.3, E868.8, E868.9, E952.1, E982.1). Probable cases were defined as any encounter with ICD-9-CM E-code indicating motor vehicle exhaust exposure (E868.2, E952.0, E982.0). Cases were further categorized by intent as unintentional, assault, intentional self-harm, or undetermined based upon ICD-9-CM E-codes or specific ICD-10-CM codes pertaining to the nature of $\mathrm{CO}$ poisoning exposure. The full list of CSTE ICD-9-CM and ICD-10-CM codes and frequency of occurrence among cases are listed in Additional file 1; Table S1.

We utilized Logical Observation Identifiers Names and Codes (LOINC) listed by the Public Health Information Network Vocabulary Access and Distribution System [21] as laboratory tests associated with CO poisoning (32160-4, 31157-1, 20563-3, 2030-5, 2031-3, 41648-7, 2032-1, and 2029-7) to determine whether carboxyhemoglobin $(\mathrm{COHb})$ blood testing of patients coded for $\mathrm{CO}$ poisoning by ICD-9-CM or ICD-10-CM was performed. A COHb measurement was considered collected at time of encounter if the date of $\mathrm{COHb}$ sample collection was within $0-2$ days before or after encounter date. 2018 CSTE laboratory criteria for confirmed/probable classification was based on $\mathrm{COHb}$ blood level $\geq 9 \%$ for probable or $>12 \%$ for confirmed cases in settings where smoking history is unknown [19]. We analyzed procedure codes ICD-9-CM 93.95 and the ICD-10 Procedure Coding System codes 5A05121 and 
5A05221 for hyperbaric oxygen $\left(\mathrm{HBO}_{2}\right)$ therapy and dates of death within intervals of 30 days or 1 year relative to $\mathrm{CO}$ poisoning encounter dates as outcome data for patients with confirmed, probable, and suspected $\mathrm{CO}$ poisoning.

\section{Statistical analysis}

We analyzed demographic variables and compared to unique users of VHA care during the 2010-2017 timeperiod, calculating 95\% CIs. Seasonality trends for CO poisoning encounters were analyzed across the study period. Rates were calculated using total unique users of VHA care for matching time frame and VHA-defined demographic category as denominator. Rates of $\mathrm{CO}$ poisoning by U.S. Census region [22] were determined based on state location of the parent facility where the encounter occurred, using number of unique users of VHA care per state. Rates for confirmed/probable cases were compared to those of suspected cases across all variables looking for potential differences based on case categorization and testing for statistical significance using the two-tailed $\mathrm{z}$ test for proportions. Statistical analysis was performed using Python Statsmodels module, version 0.9.0 [23].

We performed EMR review for 678 patients including a) all 595 confirmed/probable $\mathrm{CO}$ poisoning cases from 2010 to 2016 initially categorized with undetermined injury intent; b) a random sample of 20 patients out of 1847 (1\%) with suspected CO poisoning coded with ICD-9-CM code E825.x for "Other motor vehicle non-traffic accident of other and unspecified nature"; c) a random sample of 20 confirmed/probable cases with source of CO poisoning "other or unspecified", d) all 26 patients with confirmed/probable $\mathrm{CO}$ poisoning who died within 30 days of $\mathrm{CO}$ poisoning encounter; and e) all 17 patients who received $\mathrm{HBO}_{2}$ therapy.

\section{Results}

We identified 5491 unique patients with ICD-9-CM or ICD-10-CM encounter codes that met the 2018 CSTE criteria for confirmed, probable, or suspected $\mathrm{CO}$ poisoning. A total of 1755 (32\%) were confirmed/probable cases, while 3736 (68\%) were suspected. The average annual incidence rate for confirmed/probable $\mathrm{CO}$ poisoning was 3.6 per 100,000 unique users of VHA care (range: $3.0-4.2$ per 100,000 unique users across all years, with highest at 2010 and lowest at 2017).

Table 1 displays $\mathrm{CO}$ poisoning case characteristics, comparing confirmed/probable to suspected. Among the 1755 confirmed/probable cases, 746 (42.5\%) had unintentional injury intent, 1274 (72.6\%) were outpatient, 1556 (88.7\%), were male, 883 (50.3\%) were 45-64 years old, and 1286 (73.3\%) were white. The source of $\mathrm{CO}$ poisoning was "other or unspecified" for 1289 (73.4\%) of confirmed/ probable cases based on associated ICD-9-CM or
ICD-10-CM codes (Additional file 1). Motor vehicle exhaust was the second most common source of confirmed/ probable cases, (261 cases; 14.9\%). Less frequent sources among confirmed/probable cases were domestic fuel (101 cases; 5.8\%), utility gas (69 cases; 3.9\%), smoke/fumes from conflagration (7 cases; $0.4 \%$ ), and liquefied petroleum gas ( 6 cases; 0.3\%). Table 2 shows demographic characteristics of patients with confirmed/probable encounters compared to the overall population of unique VHA care users. Demographic factors with highest confirmed/probable $\mathrm{CO}$ poisoning rates were age groups $\leq 44$ (5.3 per $100,000 ; 95 \% \mathrm{CI}=4.8,5.8)$ and $45-64$ (5.4 per 100,000; $95 \% \mathrm{CI}=5.1,5.8)$ and residence in the Midwest (5.3 per $100,000 ; 95 \% \mathrm{CI}=5.8,5.8)$ compared to South or West (2.4 per 100,000; $95 \% \mathrm{CI}=2.2,2.7$ and 3.5 per 100,000; $95 \% \mathrm{CI}=3.1,3.9$, respectively). Figure 1 illustrates higher rates of confirmed/probable $\mathrm{CO}$ poisoning associated with self-harm in younger age groups compared to the oldest. Confirmed/probable cases did not differ from unique users of VHA care in gender or race/ethnicity.

Compared to suspected cases, confirmed/probable cases were more significantly associated with intentional self-harm and undetermined causes of injury, whereas suspected cases were more likely to be coded as unintentional $(p<0.001$ for each injury category/case classification combination except assault) (Table 1). Significant differences were also seen with race/ethnicity of confirmed/probable cases compared to suspected with more confirmed/ probable cases being white or multi-racial $(p=0.001$ and 0.01 , respectively). Confirmed/probable cases were significantly more likely to receive care in inpatient settings (26.1\% confirmed/probable versus $7.4 \%$ for suspected cases; $p<0.001)$. Additionally, 614 of 1274 (48.2\%) confirmed/ probable cases seen in the outpatient setting were ED or urgent care visits.

EMR review of 595 patients initially classified as confirmed/probable $\mathrm{CO}$ poisoning with undetermined injury intent revealed that $310(52.1 \%)$ were unintentional CO poisoning. Intentional self-harm accounted for 27 (4.5\%) while injury intent for $\mathrm{CO}$ poisoning for the remaining 258 (43.4\%) could not be determined. An additional review of 20 randomly selected EMR of confirmed/probable cases with source of $\mathrm{CO}$ poisoning "other or unspecified" revealed that 5 (25\%) in fact had a motor vehicle exhaust source. The largest percent (7 of 20 cases; $35 \%$ ) remained with source other or unspecified. Other sources were 3 smoke/fumes (15\%), 2 each utility gas and liquid propane (10\% each), and 1 incomplete combustion of domestic fuel (5\%).

Among suspected cases, ICD-9-CM code E825.x, "other motor vehicle non-traffic accident of other and unspecified nature, including accidental poisoning from carbon monoxide" was present most frequently (49.4\%) followed by E869.9, "accidental poisoning by other gases 
Table 1 Characteristics of Veterans with confirmed/probable vs. suspected carbon monoxide poisoning, 2010-2017

\begin{tabular}{|c|c|c|c|c|}
\hline \multirow[t]{2}{*}{ Characteristic } & $\begin{array}{l}\text { Confirmed and Probable } \\
N=1755\end{array}$ & $\begin{array}{l}\text { Suspected }^{a} \\
N=3736\end{array}$ & $p$-value ${ }^{b}$ & \multirow{2}{*}{$\begin{array}{l}\text { Combined } \\
N=5491 \\
\text { No. (\%) }\end{array}$} \\
\hline & No. (\%) & \multicolumn{2}{|l|}{ No. (\%) } & \\
\hline \multicolumn{5}{|l|}{ Injury Category: } \\
\hline Unintentional & $746(42.5)$ & $3259(87.2)$ & $<0.001$ & $4005(72.9)$ \\
\hline Assault & $10(0.6)$ & $19(0.5)$ & 0.77 & $29(0.5)$ \\
\hline Intentional Self-Harm & 349 (19.9) & $222(5.9)$ & $<0.001$ & $571(10.4)$ \\
\hline Undetermined & $650(37)$ & $236(6.3)$ & $<0.001$ & $886(16.1)$ \\
\hline \multicolumn{5}{|l|}{ Encounter setting: } \\
\hline Inpatient & $458(26.1)$ & $277(7.4)$ & $<0.001$ & $735(13.4)$ \\
\hline Non-VA & $23(1.3)$ & $175(4.7)$ & $<0.001$ & 198 (3.6) \\
\hline Outpatient & $1274(72.6)$ & $3284(87.9)$ & $<0.001$ & $4558(83)$ \\
\hline \multicolumn{5}{|l|}{ Gender: } \\
\hline Female & $199(11.3)$ & $419(11.2)$ & 0.89 & $618(11.3)$ \\
\hline Male & $1556(88.7)$ & $3317(88.8)$ & 0.89 & $4873(88.7)$ \\
\hline \multicolumn{5}{|l|}{ Age groups (years): } \\
\hline$\leq 44$ & $429(24.4)$ & $1077(28.8)$ & $<0.001$ & $1506(27.4)$ \\
\hline $45-64$ & $883(50.3)$ & $1704(45.6)$ & 0.001 & $2587(47.1)$ \\
\hline$\geq 65$ & $443(25.2)$ & 955 (25.6) & 0.80 & $1398(25.5)$ \\
\hline \multicolumn{5}{|l|}{ Race/Ethnicity: } \\
\hline $\mathrm{Al} / \mathrm{AN}$ & $11(0.6)$ & $29(0.8)$ & 0.54 & $40(0.7)$ \\
\hline Asian & $6(0.3)$ & $25(0.7)$ & 0.13 & $31(0.6)$ \\
\hline Black & $253(14.4)$ & $538(14.4)$ & 0.99 & $791(14.4)$ \\
\hline Hispanic/Latino & $67(3.8)$ & $188(5)$ & 0.05 & $255(4.6)$ \\
\hline Multi-racial & $19(1.1)$ & $18(0.5)$ & 0.01 & $37(0.4)$ \\
\hline $\mathrm{NH} / \mathrm{OPI}$ & $12(0.7)$ & $33(0.9)$ & 0.44 & $45(0.8)$ \\
\hline Unknown & $101(5.8)$ & $329(8.8)$ & $<0.001$ & $430(7.8)$ \\
\hline White & $1286(73.3)$ & $2576(69)$ & 0.001 & $3862(70.3)$ \\
\hline \multicolumn{5}{|l|}{$\% \mathrm{COHb}$ blood level } \\
\hline Present at time of encounter ${ }^{b}$ & $668(38)$ & $182(4.9)$ & $<0.001$ & $850(15.5)$ \\
\hline Blood level $\geq 9 \%^{c}$ & $206(30.8)$ & $8(4.4)$ & $<0.001$ & $214(25.2)$ \\
\hline \multicolumn{5}{|l|}{ Death } \\
\hline Died within 30 days of encounter & $26(1.5)$ & $2(0.1)$ & $<0.001$ & $28(0.5)$ \\
\hline Died within 1 year of encounter & $89(5.1)$ & $11(0.3)$ & $<0.001$ & $100(1.8)$ \\
\hline
\end{tabular}

Note: Al/AN, American Indian/Alaskan Native; NH/OPI, Native Hawaiian/Other Pacific Islander; $\mathrm{COHb}$, carboxyhemoglobin

a Suspected cases (based on ICD-9-CM codes only) did not occur after September 30, 2015 when coding system changed to ICD-10-CM

${ }^{\mathrm{b}}$ Performed same day, or 1-2 days before or after date of $\mathrm{CO}$ poisoning coded encounter. If more than one test was performed per unique patient, highest blood

level measurement was used

${ }^{c}$ For subgroup of patients with carboxyhemoglobin level present at time of encounter, $N=850$

or vapors, unspecified," (19.2\%). Review of 20 randomly selected EMR of patients coded with E825.x revealed that all were involved in some type of fall from, or non-collision event involving a motor vehicle (most commonly, a motorcycle); none had evidence of $\mathrm{CO}$ poisoning.

$\mathrm{CO}$ poisoning encounters demonstrated a distinct seasonal pattern, with confirmed/probable cases peaking in winter months, and decreasing in summer (Fig. 2). Two peaks, occurring in July 2010 and August 2017 vary from this pattern. However, confirmed/probable cases during these months occurred at multiple facilities across multiple states and could not be linked to specific natural disaster events. Similarly, we detected no geographic clustering of cases within seasonal peaks linked to specific events. Suspected CO poisoning encounters show a reverse seasonal pattern, with occurrence, particularly those with code E825.x, tending to peak in summer months and nadir in the winter. Since the change from 
Table 2 Demographic characteristics of Veterans with confirmed/probable carbon monoxide poisoning compared to all Veterans patients, 2010-2017

\begin{tabular}{|c|c|c|c|}
\hline \multirow[t]{2}{*}{ Characteristic } & \multicolumn{2}{|c|}{ Confirmed and Probable cases } & \multirow{2}{*}{$\begin{array}{l}\text { Unique users of } \\
\text { VHA care } \\
\text { No. users. (\%) }\end{array}$} \\
\hline & No. cases (\%) & $\begin{array}{l}\text { Rate per } 100,000 \\
\text { unique users of care }(95 \% \mathrm{Cl})\end{array}$ & \\
\hline Overall & $1755(100.0)$ & $3.6(3.5,3.8)$ & $48,461,554(100.0)$ \\
\hline \multicolumn{4}{|l|}{ Gender: } \\
\hline Female & $199(11.3)$ & $4.2(3.7,4.8)$ & $4,692,679(9.7)$ \\
\hline Male & $1556(88.7)$ & $3.6(3.4,3.7)$ & $43,664,749(90.1)$ \\
\hline Unknown & 0 & $--^{a}$ & $104,126(0.2)$ \\
\hline \multicolumn{4}{|l|}{ Age groups (years): } \\
\hline$\leq 44$ & $429(24.4)$ & $5.3(4.8,5.8)$ & $8,131,072(16.8)$ \\
\hline $45-64$ & $883(50.3)$ & $5.4(5.1,5.8)$ & $16,219,636(33.5)$ \\
\hline$\geq 65$ & $443(25.2)$ & $1.8(1.7,2.0)$ & $24,078,923(49.7)$ \\
\hline Unknown & 0 & $--^{a}$ & $31,923(0.1)$ \\
\hline \multicolumn{4}{|l|}{ Race/Ethnicity: ${ }^{b}$} \\
\hline $\mathrm{Al} / \mathrm{AN}$ & $8(0.4)$ & $--^{\mathrm{a}}$ & $167,952(0.3)$ \\
\hline Asian & $5(0.3)$ & $--^{a}$ & $254,426(0.5)$ \\
\hline Black & $156(8.9)$ & $3.4(2.9,4.0)$ & $4,555,304(9.4)$ \\
\hline Hispanic/Latino & $53(3.0)$ & $3.0(2.2,3.9)$ & $1,746,941(3.6)$ \\
\hline Multi-racial & $8(0.4)$ & $--^{\mathrm{a}}$ & $308,867(0.6)$ \\
\hline $\mathrm{NH} / \mathrm{OPI}$ & $9(0.5)$ & $--^{\mathrm{a}}$ & $180,193(0.4)$ \\
\hline Unknown & $66(3.8)$ & $1.6(1.2,2.0)$ & $4,168,179(8.6)$ \\
\hline \multirow[t]{2}{*}{ White } & $764(43.5)$ & $3.9(3.7,4.2)$ & $19,427,646(40.1)$ \\
\hline & & & $N=30,809,508$ \\
\hline \multicolumn{4}{|c|}{ U.S. Census Region: ${ }^{c}$} \\
\hline Midwest & $438(24.9)$ & $5.3(4.8,5.8)$ & $8,207,633(16.9)$ \\
\hline Northeast & $206(11.7)$ & $4.2(3.6,4.8)$ & 4,920,495 (10.2) \\
\hline South & $381(21.7)$ & $2.4(2.2,2.7)$ & $15,575,099(32.1)$ \\
\hline West & $268(15.3)$ & $3.5(3.1,3.9)$ & $7,681,621(15.9)$ \\
\hline \multirow[t]{2}{*}{ PR/VI } & $2(0.1)$ & $--^{a}$ & $374,127(1)$ \\
\hline & & & $N=36,758,975$ \\
\hline
\end{tabular}

Note: Al/AN, American Indian/Alaskan Native; NH/OPI, Native Hawaiian/Other Pacific Islander; PR/VI, Puerto Rico/Virgin Islands

${ }^{\mathrm{a}} \mathrm{Cl}$ not calculated for cell size $<10$

${ }^{b}$ Denominator data for race/ethnicity were available for 2013-2017 only, therefore rates are based on data for these years only

'Denominator data for U.S. Census region were available for 2012-2017 only, therefore rates are based on data for these years only

ICD-9-CM to ICD-10-CM systems, overall numbers of coded cases of $\mathrm{CO}$ poisoning (primarily suspected cases) appear to have dropped, with categories shifting toward more unintentional and fewer intentional self-harm and undetermined cases.

Percent $\mathrm{COHb}$ blood level measurement was performed at the time of $\mathrm{CO}$ poisoning encounter in 850 out of 5491 cases (15.5\%) (Table 2). COHb blood level measurement occurred more frequently among confirmed/probable cases (38\%), than among suspected $(4.9 \%)(p<0.001)$. A COHb level $\geq 9 \%$ was found in $30.8 \%$ of confirmed/probable cases, compared to $4.4 \%$ of patients with suspected $\mathrm{CO}$ poisoning $(p<0.001)$.
Seventeen (1\%) patients with confirmed/probable CO poisoning had $\mathrm{HBO}_{2}$ therapy based on procedure codes. No suspected $\mathrm{CO}$ poisoning cases had documented $\mathrm{HBO}_{2}$ therapy. All $\mathrm{HBO}_{2}$ treatments were performed at non-VA facilities, as VHA facilities don't provide $\mathrm{HBO}_{2}$ treatment onsite. Percent $\mathrm{COHb}$ blood level for 15 of 17 patients at the time of $\mathrm{CO}$ exposure ranged between 16 and 50\% (median 27.6\%).

More patients with confirmed/probable compared to suspected $\mathrm{CO}$ poisoning died within 30 days and within 1 year after their encounter ( 1.5 and $5.1 \%$ at 30 -day and 1 -year intervals for confirmed/probable versus 0.1 and $0.3 \%$ for suspected at 30-day and 1-year intervals, 


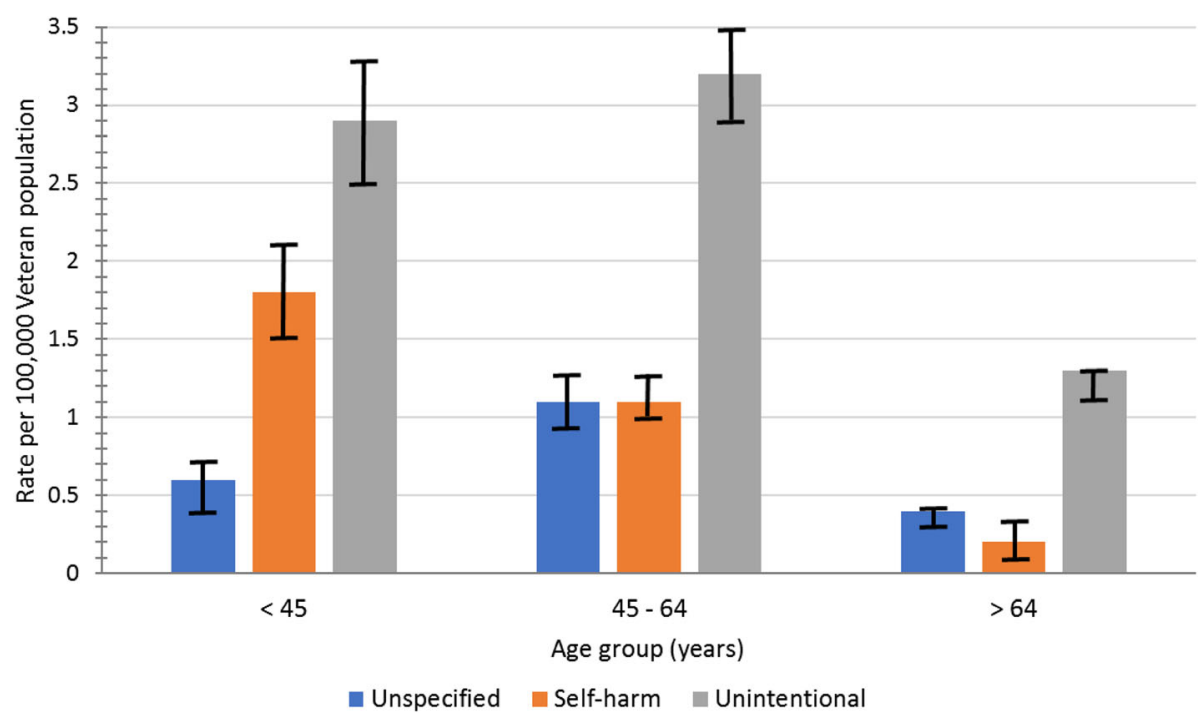

Fig. 1 Confirmed/probable carbon monoxide poisoning rates with $95 \% \mathrm{Cl}$ by injury intent and age group, 2010 - 2017. Note: Assault injury intent not included in calculations due to case numbers less than 10 per category

respectively; $p<0.001$ in both cases). Table 3 lists all confirmed/probable cases who died within 30 days of initial $\mathrm{CO}$ poisoning encounter, and their cause of death. Of $26(1.5 \%)$ confirmed/probable cases who died within 30 -day time frame, ages ranged from 30 to 85 years (median 63). Causes of death were primarily cardiovascular (11 of 26 (42\%) cases), including cardiac arrest and congestive heart failure in 3 cases each, ST-elevation myocardial infarction and inferior wall myocardial infarction in 2 cases each, and 1 stroke). Anoxic brain injury occurred in 4 of 26 (15\%) cases, one of whom was unsuccessfully treated with $\mathrm{HBO}_{2}$ after $\mathrm{CO}$ poisoning exposure during a house fire. Repeat successful suicide attempt by more lethal means (following original unsuccessful attempt using $\mathrm{CO}$ ), lung disease, and cases whose EMR documentation was inadequate to allow determination of cause of death followed with 3 each (3 of 26 (12\%) for each category). Acute kidney injury was least common with 2 of 26 (8\%) cases.

\section{Discussion}

We determined that from 2010 through 2017, the average annual rate for $\mathrm{CO}$ poisoning among Veterans was 3.6 confirmed/probable cases per 100,000 unique users of VHA care. Our study focused on Veterans receiving care in VHA and does not exclude fire-related or intentional $\mathrm{CO}$ poisoning exposures, therefore the annual rate of confirmed/probable $\mathrm{CO}$ cases must be viewed in that context when compared to national UNFR rates based on U.S population estimates. Nevertheless, some useful comparisons can be made.

We detected significant differences between confirmed/ probable and suspected $\mathrm{CO}$ poisoning cases, indicating that confirmed/probable are likely more severely affected (i.e. presence of $\mathrm{COHb}$ blood level $\geq 9 \%$, more frequent inpatient encounters, treatment with $\mathrm{HBO}_{2}$, increased frequency of death within 30 days or 1 year of initial encounter) than cases classified as suspected. We found that confirmed/probable cases were more likely to be associated with intentional self-harm and undetermined injury categories. However, in our review of a subset of 595 confirmed/probable cases with undetermined injury intent, $53 \%$ represented unintentional cases, so the unintentional category of injury may have been underrepresented among our confirmed/probable $\mathrm{CO}$ poisoning cases. Underreporting of $\mathrm{CO}$ poisoning source also occurred, however our review of 20 randomly selected EMR of confirmed/probable cases with source of $\mathrm{CO}$ poisoning "other or unspecified" revealed occurrence of sources comparable to those of the complete cohort.

Our demographic trends for confirmed/probable $\mathrm{CO}$ poisoning were consistent with some previous studies, with younger age groups being more affected $[1,24,25]$, and location in Midwest U.S. Census regions [1, 26, 27]. Although other studies reported higher rates among older age groups and females, we did not see this increase in our study. Our analysis showing association of confirmed/probable CO poisoning cases with self-harm, and the increased incidence of suicide among younger Veterans [15] may partially explain this finding. However, differing methodologies such as exclusion of intentional and non-fire-related injuries, and inclusion of mortality data may make comparisons with these studies problematic $[26,28]$.

Confirmed/probable cases followed the established cold weather seasonal trends commonly associated with $\mathrm{CO}$ 


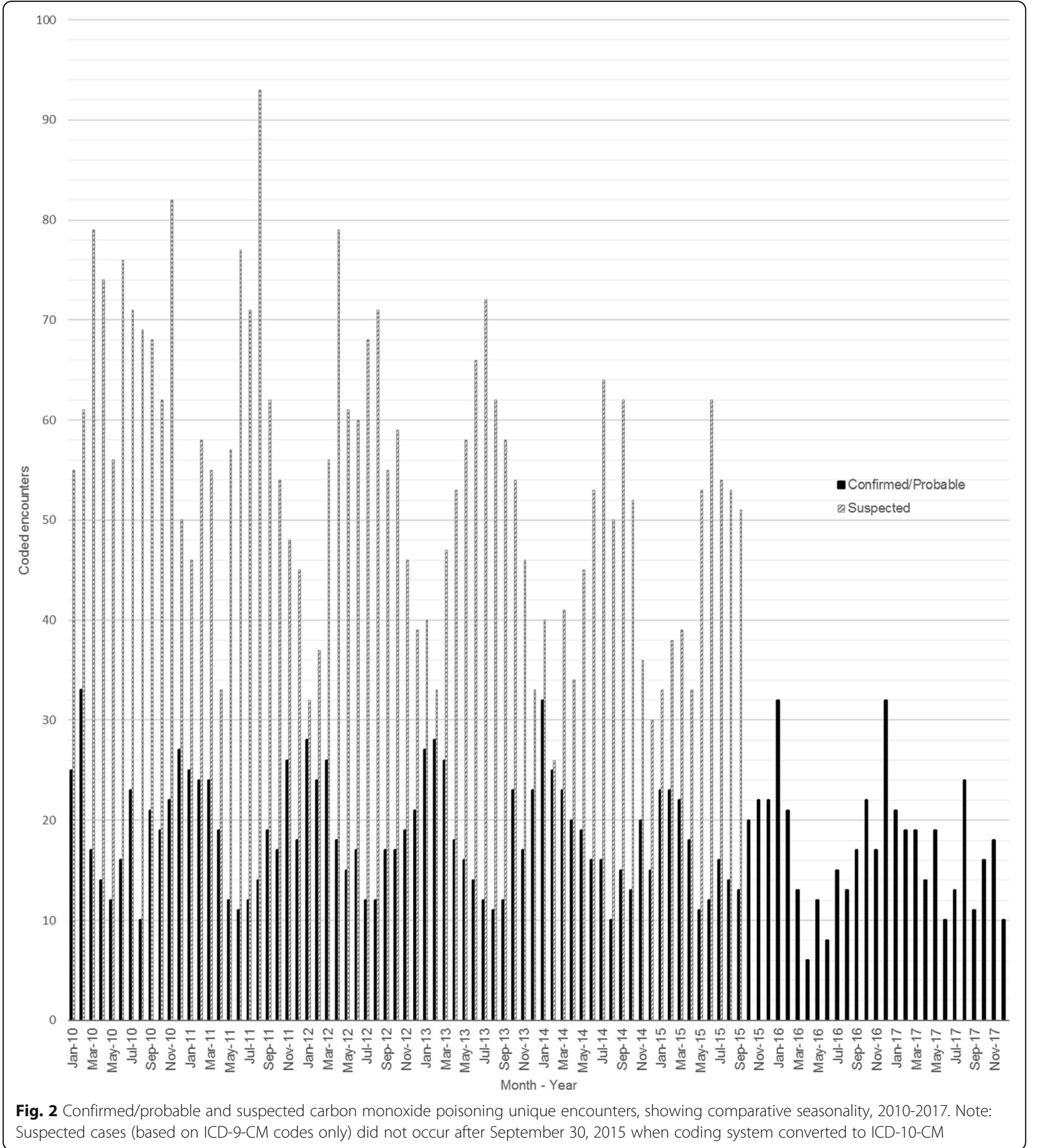

poisoning $[24,29]$, while suspected cases followed a distinctly opposite trend. The summer seasonal trend shown by the suspected $\mathrm{CO}$ poisoning cases may be explained by the relatively high frequency of the E825.x code, which our EMR review indicated may be more indicative of motorcycle and other motor vehicle type-associated non-collision events than $\mathrm{CO}$ poisoning. These events could be expected to peak during summer months [30]. If our EMR review of 20 encounters with an E825.x code was representative of all 1847 cases classified as such, then approximately half of the suspected cases in our cohort were likely not true cases. The transition in October 2015 from ICD-9-CM to ICD-10-CM effectively removed the suspected $\mathrm{CO}$ poisoning category from consideration 
Table 3 Causes of death for carbon monoxide poisoning cases who died within 30 days of encounter, 2010-2017

\begin{tabular}{|c|c|c|c|c|c|}
\hline Age & $\begin{array}{l}\text { \# Days, } \\
\text { encounter } \\
\text { until death }\end{array}$ & $\begin{array}{l}\text { ICD Exposure } \\
\text { Code }\end{array}$ & Code description; injury category & Cause of death & Category of death \\
\hline 60 & 1 & E890.2 & $\begin{array}{l}\text { Other smoke and fumes from conflagration in a } \\
\text { private dwelling, including carbon monoxide; } \\
\text { unintentional }\end{array}$ & Anoxic brain injury & Anoxic brain injury \\
\hline 30 & 0 & T58.02X & $\begin{array}{l}\text { Toxic effect of carbon monoxide from motor vehicle } \\
\text { exhaust; intentional self-harm }\end{array}$ & $\begin{array}{l}\text { Death by suicide (original } \\
\text { attempt) }\end{array}$ & Anoxic brain injury \\
\hline 62 & 25 & 986 & Toxic effect of carbon monoxide; undetermined & Anoxic brain injury & Anoxic brain injury \\
\hline 78 & 28 & 986 & Toxic effect of carbon monoxide; undetermined & Anoxic brain injury & Anoxic brain injury \\
\hline 63 & 8 & E868.8 & $\begin{array}{l}\text { Accidental poisoning by carbon monoxide from other } \\
\text { sources; unintentional }\end{array}$ & $\begin{array}{l}\text { STEMI (ST - elevation myocardial } \\
\text { infarction) }\end{array}$ & Cardiovascular \\
\hline 70 & 21 & T58.01X & $\begin{array}{l}\text { Toxic effect of carbon monoxide from motor vehicle } \\
\text { exhaust; unintentional }\end{array}$ & Congestive heart failure & Cardiovascular \\
\hline 81 & 3 & T58.8X1 & $\begin{array}{l}\text { Toxic effect of carbon monoxide from other source; } \\
\text { unintentional }\end{array}$ & Myocardial infarction & Cardiovascular \\
\hline 67 & 8 & T58.91X & $\begin{array}{l}\text { Toxic effect of carbon monoxide from unspecified } \\
\text { source; } \\
\text { unintentional }\end{array}$ & $\begin{array}{l}\text { STEMI (ST - elevation myocardial } \\
\text { infarction) }\end{array}$ & Cardiovascular \\
\hline 63 & 1 & 986 & Toxic effect of carbon monoxide; undetermined & Inferior wall myocardial infarction & Cardiovascular \\
\hline 61 & 2 & 986 & Toxic effect of carbon monoxide; undetermined & Cardiac arrest & Cardiovascular \\
\hline 67 & 8 & 986 & Toxic effect of carbon monoxide; undetermined & Congestive heart failure & Cardiovascular \\
\hline 38 & 10 & 986 & Toxic effect of carbon monoxide; undetermined & Cardiac arrest & Cardiovascular \\
\hline 63 & 13 & 986 & Toxic effect of carbon monoxide; undetermined & Stroke & Cardiovascular \\
\hline 66 & 19 & 986 & Toxic effect of carbon monoxide; undetermined & Congestive heart failure & Cardiovascular \\
\hline 53 & 30 & 986 & Toxic effect of carbon monoxide; undetermined & Cardiac arrest & Cardiovascular \\
\hline 85 & 0 & E868.9 & $\begin{array}{l}\text { Accidental poisoning by carbon monoxide from } \\
\text { unspecified source; unintentional }\end{array}$ & Acute kidney injury & Kidney injury \\
\hline 69 & 6 & T58.11X & $\begin{array}{l}\text { Toxic effect of carbon monoxide from utility gas; } \\
\text { unintentional }\end{array}$ & Acute kidney injury & Kidney injury \\
\hline 68 & 11 & 986 & Toxic effect of carbon monoxide; undetermined & Lung cancer & Lung disease \\
\hline 63 & 24 & 986 & Toxic effect of carbon monoxide; undetermined & End-stage COPD & Lung disease \\
\hline 63 & 25 & 986 & Toxic effect of carbon monoxide; undetermined & End-stage COPD & Lung disease \\
\hline 52 & 21 & E952.1 & $\begin{array}{l}\text { Self-inflicted poisoning by other carbon monoxide } \\
\text { source; intentional self-harm }\end{array}$ & $\begin{array}{l}\text { Self-inflicted poisoning, carbon } \\
\text { monoxide }\end{array}$ & $\begin{array}{l}\text { Suicide - repeat } \\
\text { attempt }\end{array}$ \\
\hline 43 & 27 & E952.1 & $\begin{array}{l}\text { Self-inflicted poisoning by other carbon monoxide } \\
\text { source; intentional self-harm }\end{array}$ & $\begin{array}{l}\text { Death by suicide (new attempt, } \\
\text { different method) }\end{array}$ & $\begin{array}{l}\text { Suicide - repeat } \\
\text { attempt }\end{array}$ \\
\hline 57 & 9 & T58.92X & $\begin{array}{l}\text { Toxic effect of carbon monoxide from unspecified } \\
\text { source; intentional self-harm }\end{array}$ & $\begin{array}{l}\text { Death by suicide (new attempt, } \\
\text { different method) }\end{array}$ & $\begin{array}{l}\text { Suicide - repeat } \\
\text { attempt }\end{array}$ \\
\hline 60 & 18 & E868.9 & $\begin{array}{l}\text { Accidental poisoning by carbon monoxide from an } \\
\text { unspecified source; unintentional }\end{array}$ & $\begin{array}{l}\text { Unknown (inadequate chart } \\
\text { documentation) }\end{array}$ & Unknown \\
\hline 63 & 26 & E868.1 & $\begin{array}{l}\text { Accidental poisoning by other/unspecified utility gas, } \\
\text { or carbon monoxide from combustion of such gas; } \\
\text { unintentional }\end{array}$ & $\begin{array}{l}\text { Unknown (inadequate chart } \\
\text { documentation) }\end{array}$ & Unknown \\
\hline 70 & 8 & T58.91X & $\begin{array}{l}\text { Toxic effect of carbon monoxide from unspecified } \\
\text { source; unintentional }\end{array}$ & $\begin{array}{l}\text { Unknown (inadequate chart } \\
\text { documentation) }\end{array}$ & Unknown \\
\hline
\end{tabular}

going forward within VHA. Findings like these in which disease surveillance trends shift as a result of coding differences before and after the U.S. transition from ICD-9-CM to ICD-10-CM are not unusual, and can make year-to-year comparisons challenging [31].
Studies showing elevated risk of short-term and long-term mortality after $\mathrm{CO}$ poisoning, especially with respect to adverse cardiovascular events, shared similarity with our results $[14,32-34]$. One concerning finding of our study was that of 3 patients who attempted suicide 
using $\mathrm{CO}$, they successfully repeated their attempt within 30 days, using more lethal means. Given the increased rates of suicide among Veterans, VHA has targeted for improvement specific methods to follow-up and prevent suicide in patients deemed high-risk [35].

\section{Limitations}

Our study has several limitations. In limiting cases to those coded with ICD-9-CM or ICD-10-CM CO poisoning codes, we may have omitted those miscoded or not coded. In addition, clinicians may not have considered $\mathrm{CO}$ poisoning when patients presented to the ED. Previous studied have found that $3-5 \%$ of patients presenting with headache and dizziness had occult $\mathrm{CO}$ poisoning [36], and therefore could have contributed to fewer cases found in our study. We did not include National Death Index data, so patients who died from their $\mathrm{CO}$ poisoning before receiving treatment at a VHA hospital are not included in our study. While we attempted to limit inclusion of miscoded cases caused by carry-over of historic exposure codes, we cannot be sure that all cases represented current diagnoses of $\mathrm{CO}$ poisoning. Conversely, our method of limiting cases to initial occurrence only may have eliminated cases that represented true second exposures, for example, repeat suicide attempts or unintentional exposures in homes where original source of $\mathrm{CO}$ has not been remediated. Our review of cases classified as "undetermined" indicates misuse of this category code may have led to underrepresentation of unintentional and intentional injury intent categories of $\mathrm{CO}$ poisoning in our study. Similarly, we found a high percentage of cases coded with an "other or unspecified" source of $\mathrm{CO}$ poisoning. Our evaluation of $\mathrm{COHb}$ blood values was likely limited by the fact that initial exposure to $\mathrm{CO}$ is often measured at the scene of $\mathrm{CO}$ exposure by first responders using pulse CO-oximetry. These values, and those of patients transferred to non-VA emergency care are scanned into the Veterans' EMR and thus not available as discrete, electronically queriable LOINC codes. Our review of the 17 cases treated with $\mathrm{HBO}_{2}$ indicates that $\mathrm{COHb}$ levels at time of treatment and recorded within scanned documents were much higher than measurements available in the EMR for those patients. Capture of $\mathrm{HBO}_{2}$ treatment may be similarly limited as it is routinely performed at non-VA sites.

\section{Conclusions}

$\mathrm{CO}$ poisoning is important for targeted public health surveillance in VHA. Despite the pitfalls of an administrative, ICD code-based surveillance system, its advantages are that it can be implemented nationally with relatively few resources, and that it provides useful, actionable information. Improvements are needed in ICD coding to reduce the percentage of cases coded with unknown injury intent and/or $\mathrm{CO}$ poisoning source. Opportunities exist to implement VHA-wide provider education to better recognize signs, symptoms, and exposure history for $\mathrm{CO}$ poisoning; and patient education programs addressing identified areas of high-risk for CO poisoning among Veterans, augmenting the VA Disaster Preparedness Manual, which contains useful information on preventing exposure to $\mathrm{CO}$. [37] Examination of $\mathrm{CO}$ poisoning suicide attempts to prevent progression to more lethal means may be an area of further study.

\section{Additional file}

Additional file 1: Table S1. Occurrence of ICD-9-CM and ICD-10-CM codes for classification of carbon monoxide poisoning cases among Veterans, 2010-2017 (DOCX $21 \mathrm{~kb}$ )

\section{Abbreviations \\ CO: Carbon monoxide; COHb: carboxyhemoglobin; CSTE: Council of State and Territorial Epidemiologists; ED: emergency department; EMR: electronic medical record; $\mathrm{HBO}_{2}$ : hyperbaric oxygen; ICD: International Classification of Diseases; ICD-10-CM: International Classification of Diseases, 10th revision, Clinical Modification; ICD-9-CM: International Classification of Diseases, 9th revision, Clinical Modification; UNFR: unintentional, non-fire related; VA: Department of Veterans Affairs; VHA: Veterans Health Administration}

\section{Acknowledgements}

We thank Steven C. Macdonald for critical review of this manuscript and Anoshiravan Mostaghimi for assistance with statistical analysis. The views expressed in this article are those of the authors and do not necessarily reflect the position or policy of the Department of Veterans Affairs or the U.S. government.

\section{Funding}

This work was carried out using Department of Veterans Affairs intramural funding, and was not funded by external sources.

\section{Availability of data and materials}

The datasets used and/or analyzed during this study are available from the corresponding author on reasonable request.

\section{Disclaimer}

The views expressed in this manuscript are those of the authors and do not necessarily reflect the position or policy of the Department of Veterans Affairs or the United States government.

\section{Authors' contributions}

GO contributed to study conception, design, data analysis, and the writing of the manuscript. RR contributed to study design, data analysis, and critical review. $\mathrm{CL}-\mathrm{O}, \mathrm{PS}$, and $\mathrm{MH}$ contributed to study design and critical review. All the authors read, edited and approved the final manuscript.

\section{Ethics approval and consent to participate}

All data was accessed as part of ongoing public health surveillance activities and was therefore considered exempt from consent to participate by the Veterans Health Administration Office of Research Oversight which considers public health investigations as operational activities and not research in the Veterans Health Administration. Permission to access data was granted through the Veterans Health Administration Director of National Data Systems, Austin Information Technology Center, 1615 Woodward Street, Austin, Texas 78,772, in accordance with the Privacy Act of 1974; System of Records entitled, "National Patient Databases - VA" (121VA10A7). 


\section{Consent for publication}

Not applicable.

\section{Competing interests}

The authors declare that they have no competing interests.

\section{Publisher's Note}

Springer Nature remains neutral with regard to jurisdictional claims in published maps and institutional affiliations.

\section{Author details}

'Public Health Surveillance and Research, Department of Veterans Affairs, 3801 Miranda Avenue (132), Palo Alto, CA 94304, USA. ${ }^{2}$ Division of Infectious Diseases and Geographic Medicine, Stanford University, Stanford, CA, USA.

Received: 26 November 2018 Accepted: 1 February 2019

Published online: 14 February 2019

\section{References}

1. Centers for Disease Control and Prevention. Carbon monoxide exposures--United States, 2000-2009. MMWR Morb Mortal Wkly Rep. 2011;60(30):1014-1017. https://www.cdc.gov/mmwr/preview/mmwrhtml/ mm6030a2.htm?s_cid=mm6030a2_w

2. Sircar K, Clower J, Shin MK, Bailey C, King M, Yip F. Carbon monoxide poisoning deaths in the United States, 1999 to 2012. Am J Emerg Med. 2015:33(9):1140-1145. doi.org/https://doi.org/10.1016/.ajem.2015.05.002

3. Iqbal S, Law HZ, Clower JH, Yip FY, Elixhauser A. Hospital burden of unintentional carbon monoxide poisoning in the United States, 2007. Am J Emerg Med. 2012;30(5):657-664. doi.org/https://doi.org/10.1016/j. ajem.2011.03.003

4. Hampson NB, Weaver LK. Carbon monoxide poisoning: a new incidence for an old disease. Undersea Hyperb Med. 2007;34(3):163-8.

5. Centers for Disease Control and Prevention. Carbon Monoxide Poisoning Routine Surveillance. 2018; https://www.cdc.gov/co/surveillance/routine. htm. Accessed 9 May 2018.

6. Iqbal S, Clower JH, Boehmer TK, Yip FY, Garbe P. Carbon monoxide-related hospitalizations in the U.S.: evaluation of a web-based query system for public health surveillance. Public Health Rep. 2010;125(3):423-432. doi.org/ https://doi.org/10.1177/003335491012500311

7. Ball LB, Macdonald SC, Mott JA, Etzel RA. Carbon monoxide-related injury estimation using ICD-coded data: methodologic implications for public health surveillance. Arch Environ Occup Health. 2005;60(3):119-127. doi.org/ https://doi.org/10.3200/aeoh.60.3.119-127

8. Weaver LK, Deru K, Churchill S, Legler J, Snow G, Grey T. Carbon monoxide poisoning in Utah: 1996-2013. Undersea Hyperb Med. 2016;43(7):747-58.

9. Harduar-Morano L, Watkins S. Review of unintentional non-fire-related carbon monoxide poisoning morbidity and mortality in Florida, 1999-2007. Public Health Rep. 2011;126(2):240-250. doi.org/https://doi.org/10.1177/ 003335491112600215

10. Wheeler-Martin K, Soghoian S, Prosser JM, et al. Impact of Mandatory Carbon Monoxide Alarms: An Investigation of the Effects on Detection and Poisoning Rates in New York City. Am J Public Health. 2015;105(8): 1623-1629. doi.org/https://doi.org/10.2105/ajph.2015.302577

11. Veterans Health Administration. About VHA. 2018; https://www.va.gov/ health/aboutVHA.asp. Accessed 14 May 2018.

12. Assari S. Veterans and risk of heart disease in the United States: a cohort with 20 years of follow up. Int J Prev Med. 2014;5(6):703-709. https://www. ncbi.nlm.nih.gov/pmc/articles/PMC4085922/. Accessed 19 Dec 2018.

13. Cypel YS, Hamlett-Berry K, Barth SK, et al. Cigarette Smoking and Sociodemographic, Military, and Health Characteristics of Operation Enduring Freedom and Operation Iraqi Freedom Veterans: 2009-2011 National Health Study for a New Generation of US Veterans. Public Health Rep. 2016;131(5):714-727. doi.org/https://doi.org/10.1177/ 0033354916664864

14. Huang $\mathrm{CC}$, Chung MH, Weng SF, et al. Long-term prognosis of patients with carbon monoxide poisoning: a nationwide cohort study. PloS one. 2014; 9(8):e105503. doi.org/https://doi.org/10.1371/journal.pone.0105503

15. Blow FC, Bohnert AS, llgen MA, et al. Suicide mortality among patients treated by the Veterans Health Administration from 2000 to 2007. Am J Public Health. 2012;102 Suppl 1:S98-104. doi.org/https://doi.org/10.2105/ ajph.2011.300441
16. McCarthy JF, Valenstein M, Kim HM, Ilgen M, Zivin K, Blow FC. Suicide mortality among patients receiving care in the veterans health administration health system. Am J Epidemiol. 2009;169(8):1033-1038. doi. org/https://doi.org/10.1093/aje/kwp010

17. Hampson NB, Holm JR. Suicidal carbon monoxide poisoning has decreased with controls on automobile emissions. Undersea Hyperb Med. 2015;42(2): $159-64$.

18. Mott JA, Wolfe Ml, Alverson CJ, et al. National vehicle emissions policies and practices and declining US carbon monoxide-related mortality. JAMA. 2002; 288(8):988-995. doi.org/https://doi.org/10.1001/jama.288.8.988

19. Council of State and Territorial Epidemiologists. Standardized Surveillance for Carbon Monoxide Poisoning. 18-EH-01. 2018. https://www.cste.org/ page/PositionStatements. Accessed 21 Aug 2018.

20. U.S. Department of Veterans Affairs. Office of Research Oversight. VHA Program Guide 1200.21: VHA Operations Activities That May Constitute Research. 2018; https://www.research.va.gov/resources/policies/handbooks. cfm. Accessed 20 Nov 2018.

21. Centers for Disease Control and Prevention. Lab tests associated with carbon monoxide poisoning. Public Health Information Network Vocabulary Access and Distribution System (PHIN VADS) 2018; https://phinvads.cdc.gov/ vads/NiewValueSet.action?id=09B9B439-6AFE-461C-B0E0-A835EFFD13E2\#. Accessed 14 May 2018.

22. U.S. Census Bueau. Geography atlas - regions. 2015. https://www.census. gov/geo/reference/webatlas/regions.html. Accessed 21 Aug 2018.

23. Seabold S, Perktold J. Statsmodels: Econometric and statistical modeling with python. Proceedings of the 9th Python in Science Conference. 2010. http://conference.scipy.org/proceedings/scipy2010/seabold.html. Accessed 22 Oct 2018.

24. Centers for Disease Control and Prevention. Nonfatal, unintentional, non-fire-related carbon monoxide exposures--United States, 2004-2006. MMWR Morb Mortal Wkly Rep. 2008;57(33):896-899. https:/www.cdc.gov/mmwr/ preview/mmwrhtml/mm5733a2.htm.

25. Clower JH, Hampson NB, lqbal S, Yip FY. Recipients of hyperbaric oxygen treatment for carbon monoxide poisoning and exposure circumstances. Am J Emerg Med. 2012;30(6):846-851. doi.org/https://doi.org/10.1016/j.ajem. 2011.05.028

26. labal S, Clower JH, King M, Bell J, Yip FY. National carbon monoxide poisoning surveillance framework and recent estimates. Public Health Rep. 2012;127(5):486-496. doi.org/https://doi.org/10.1177/003335491212700504

27. Centers for Disease Control and Prevention. Unintentional non-fire-related carbon monoxide exposures--United States, 2001-2003. MMWR Morb Mortal Wkly Rep. 2005;54(2):36-39. https://www.cdc.gov/mmwr/preview/ mmwrhtml/mm5402a2.htm

28. Graber JM, Smith AE. Results from a state-based surveillance system for carbon monoxide poisoning. Public Health Rep. 2007;122(2):145-154. doi. org/https://doi.org/10.1177/003335490712200203

29. Lavigne E, Weichenthal S, Wong J, Smith-Doiron M, Dugandzic R, Kosatsky T. Mortality and hospital admission rates for unintentional nonfire-related carbon monoxide poisoning across Canada: a trend analysis. CMAJ Open. 2015;3(2):E223-230. doi.org/https://doi.org/10.9778/cmajo.20140122

30. Insurance Institue for Highway Safety, Highway Loss Institute. Motorcyclist deaths by month, 2016. 2018; http://www.iihs.org/iihs/topics/t/motorcycles/ fatalityfacts/motorcycles\#When-and-where-they-died. Accessed 29 May 2018.

31. Khera R, Dorsey KB, Krumholz HM. Transition to the ICD-10 in the United States: An Emerging Data Chasm. JAMA. 2018. doi.org/https://doi.org/10. 1001/jama.2018.6823

32. Henry CR, Satran D, Lindgren B, Adkinson C, Nicholson Cl, Henry TD. Myocardial injury and long-term mortality following moderate to severe carbon monoxide poisoning. JAMA. 2006;295(4):398-402. doi.org/https://doi. org/10.1001/jama.295.4.398

33. Hampson NB, Hauff NM. Risk factors for short-term mortality from carbon monoxide poisoning treated with hyperbaric oxygen. Crit Care Med. 2008; 36(9):2523-2527. doi.org/https://doi.org/10.1097/CCM.0b013e31818419d8

34. Wong $C S$, Lin $Y C$, Sung $L C$, et al. Increased long-term risk of major adverse cardiovascular events in patients with carbon monoxide poisoning: A population-based study in Taiwan. PloS one. 2017;12(4):e0176465. doi.org/ https://doi.org/10.1371/journal.pone.0176465

35. Department of Veterans Affairs Inspector General. Evaluation of Suicide Prevention Programs in Veterans Health Administration Facilities 2017; https:// www.va.gov/oig/pubs/NAOIG-16-03808-215.pdf. Accessed 9 May 2018. 
36. Heckerling PS, Leikin JB, Maturen A. Occult carbon monoxide poisoning: validation of a prediction model. Am J Med. 1988;84(2):251-6.

37. Department of Veterans Affairs VHA. Disaster Preparedness Manual. U.S. Department of Veterans Affairs; 2015. https://bookstore.gpo.gov/products/ disaster-preparedness-manual-natural-diasters-man-made-disasters-patientfact-sheets. Accessed 21 Aug 2018.

Ready to submit your research? Choose BMC and benefit from:

- fast, convenient online submission

- thorough peer review by experienced researchers in your field

- rapid publication on acceptance

- support for research data, including large and complex data types

- gold Open Access which fosters wider collaboration and increased citations

- maximum visibility for your research: over $100 \mathrm{M}$ website views per year

At $\mathrm{BMC}$, research is always in progress.

Learn more biomedcentral.com/submissions 